\title{
ATENDIMENTO EDUCACIONAL ESPECIALIZADO PARA MICROCEFALIA: UMA REFLEXÃO PARA EDUCAÇÃO INCLUSIVA
}

\author{
SPECIALIZED EDUCATIONAL SERVICE FOR MICROCEPHALY: A \\ REFLECTION FOR INCLUSIVE EDUCATION
}

\author{
ATENDIMIENTO EDUCACIONAL ESPECIALIZADO PARA \\ MICROCEFALIA: UNA REFLEXIÓN PARA LA EDUCACIÓN \\ INCLUSIVA
}

DOI: http://dx.doi.org/10.5965/1984317816012020216

Simone Regina Alves de Freitas Barros Hospital Universitário de Alagoas simoninhabarros2010@hotmail.com

Pedro Henrique Falcão

Universidade Estadual de Pernambuco pedro.falcao@upe.br

\begin{abstract}
RESUMO
Em 2015 ocorreu estado de emergência sanitária nacional devido a um surto em Pernambuco de neonatos com microcefalia. O objetivo desse estudo foi analisar as ações acerca do processo de inclusão de crianças com microcefalia no ensino regular. Foram selecionados estudos disponíveis nas bases de dados da SciELO e Google Acadêmico, no idioma português. Localizados 203 estudos, desses 196 não responderam à questão norteadora o que resultou na seleção de sete estudos. Observou-se nos estudos que a inclusão escolar desses alunos perpassa por diversos problemas: inadequação do ambiente físico, falta de recursos pedagógicos, materiais escolares necessários e profissionais especializados. Ainda constatou-se a necessidade dos municípios e estados definirem políticas educacionais que possam garantir desde a matrícula em creche e pré-escolas à oferta de Atendimento Educacional Especializado. E, por fim, observou-se que os estudos sobre a inclusão escolar dos alunos com microcefalia ainda se encontram com pouca representatividade, sendo necessário um maior fomento em pesquisas que deem visibilidade a esse público, mas, também, é imprescindível investimento na formação dos recursos humanos para contribuírem na construção de melhores resultados frente ao processo de inclusão.
\end{abstract}

Palavras-chave: Educação Inclusiva. Microcefalia. Intervenção Precoce.

\begin{abstract}
In 2015, a national health emergency occurred in Pernambuco, Brazil, because of an outbreak of neonates with microcephaly. The objective of this study was to analyze the actions undertaken with regard to the inclusion of children with microcephaly in regular education. We selected studies available in the databases of SciELO included in other libraries, such as Medline, Pubmed and Lilacs) and Google Academic. In total, 203 studies were located, of which 196 did not respond to the study's guiding question, which resulted into the selection of seven studies. It was observed from these studies that the school inclusion of students with microcephaly faces the following problems: inadequate physical environment, lack of pedagogical resources, necessary school materials, and specialized professionals. The need for municipalities and states to define educational policies that can guarantee education right from enrollment in kindergarten and pre-schools to offering Specialized Educational Attendance was also verified. Finally, it was observed that studies
\end{abstract}


on the inclusion of students with microcephaly are still poorly represented and thus more research is required to make this public more visible. However, investment in the training of human resources to contribute to the construction of better results in the process of inclusion is also required.

Keywords: Educational Inclusion; Microcephaly; Early intervention.

\section{RESUMEN}

En 2015, se produjo una emergencia nacional de salud en Pernambuco, Brasil, debido a un brote de neonatos con microcefalia. El objetivo de este estudio fue analizar las acciones emprendidas con respecto a la inclusión de niños con microcefalia en la educación regular. Seleccionamos los estudios disponibles en las bases de datos de SciELO incluidas en otras bibliotecas, como Medline, Pubmed y Lilacs) y Google Academic. En total, se localizaron 203 estudios, de los cuales 196 no respondieron a la pregunta guía del estudio, lo que dio lugar a la selección de siete estudios. Se observó a partir de estos estudios que la inclusión escolar de estudiantes con microcefalia se enfrenta a los siguientes problemas: entorno físico inadecuado, falta de recursos pedagógicos, materiales escolares necesarios y profesionales especializados. También se verificó la necesidad de que los municipios y los estados definan políticas educativas que puedan garantizar la educación desde la inscripción en el jardín de infantes y las escuelas preescolares hasta la oferta de Asistencia educativa especializada. Finalmente, se observó que los estudios sobre la inclusión de estudiantes con microcefalia todavía están poco representados y, por lo tanto, se requieren más investigaciones para que este público sea más visible. Sin embargo, también se requiere inversión en la capacitación de recursos humanos para contribuir a la construcción de mejores resultados en el proceso de inclusión.

Palabras clave: Inclusión Educativa; Microcefalia; Intervención temprana;

\section{INTRODUÇÃO}

No Brasil em 2015 nos deparamos com um elevado número de crianças nascidas com microcefalia. Em novembro desse mesmo ano, o Ministério da Saúde declarou estado de emergência sanitária nacional devido a um surto no Estado de Pernambuco que registrou o maior número de casos (804). Em seguida estão os estados de Paraíba (316), Bahia (180), Rio Grande do Norte (106), Sergipe (96), Alagoas (81), Ceará (40), Maranhão (37), Piauí (36), Tocantins (29), Rio de Janeiro (23), Mato Grosso do Sul (9), Goiás (3) e Distrito Federal (1) (LIMA, et al., 2017).

A grande incidência de casos inquietou profissionais de saúde e cientistas que ainda não tinham respostas acerca das possíveis causas para tal epidemia que se instalava. Logo, deu-se início a um período de intensas pesquisas em busca de maior compreensão sobre os fatores etiológicos da microcefalia que confirmaram a relação entre a infecção materna pelo vírus Zika, no período da gravidez, e esta malformação (BARROS et al., 2017). 
O Zika Vírus é responsável por atacar células cerebrais fetais, conhecidas como células progenitoras neurais. Elas são responsáveis pela formação dos ossos e da cartilagem do crânio, por isso há uma má-formação craniana. Porém, a microcefalia não é apenas um problema físico, onde os indivíduos apresentam uma diminuição do perímetro cefálico, mas também neurológico psíquico e motor. O nível da sequela vai variar de um caso para outro, de acordo com a área cerebral atingida. Um indivíduo com microcefalia poderá ter um déficit cognitivo, problemas visuais, déficit auditivos e motores, atraso no desenvolvimento neuropsicomotor e epilepsia (LIMA, et al., 2017).

As anomalias congênitas, incluindo as microcefalias, têm etiologia complexa e multifatorial, e podem ser causadas por anomalias cromossômicas, exposições a teratógenos ambientais, doenças metabólicas, bem como por doenças maternas durante a gravidez. Podem ser primárias, se presentes ao nascimento, ou secundárias, quando se desenvolvem após o nascimento (MARINHO, 2016).

No entanto, a microcefalia é considerada uma malformação congênita evidenciada pelo não desenvolvimento do cérebro de maneira adequada onde o perímetro cefálico apresenta-se substancialmente menor, quando comparado aos de outras crianças do mesmo sexo, idade ou tempo de gestação (ASHWAL, 2009).

O diagnóstico da microcefalia é dado pela medida do crânio, realizada, pelo menos, 24 horas após o nascimento e dentro da primeira semana de vida (até 6 dias e 23 horas), por meio de técnicas e equipamentos padronizados, segundo orientação da Organização Mundial da Saúde (OMS). A medida de referência do Perímetro Cefálico é de 30,54 centímetros para meninos, e de 30,24 centímetros para meninas, com base na escala de Intergrowth (DA SILVA et al., 2018).

A microcefalia tem sido associada a uma série de fatores, compreendendo síndromes metabólicas e/ou genéticas, agressões ambientais e causas ainda desconhecidas que podem afetar o desenvolvimento do cérebro e se associar à malformação. No entanto, a mesma também pode ser ocasionada por infecções no período pré-natal como a toxoplasmose, sífilis, rubéola, citomegalovírus e herpes (DA SILVA et al., 2018). 
Embora a microcefalia não seja uma síndrome nova, sendo esta admitida pela ciência estar ligada a fatores congênitos e pós-natal o que de fato é novo seria a ligação do Zika como fator também de causa de microcefalia (SANTOS, 2016).

No contexto escolar, os indivíduos com microcefalia comumente apresentam dificuldades de aprendizagem, demandando a necessidade de acompanhamento por profissionais que possam criar ambientes de aprendizagens diferentes, proporcionando a esse aluno compreender suas dificuldades superando suas limitações (BERODT, 2013). A criança com microcefalia pode apresentar atraso mental, alterações físicas como dificuldade para andar, problemas de fala e hiperatividade ou convulsões. Porém, estas consequências da doença não surgem em todos os casos e, algumas crianças podem se desenvolver normalmente e ter uma inteligência normal porque isso depende da gravidade da sua microcefalia (MARCELLI; COHEN, 2010).

Para crianças diferentes, educação diferente, reza um princípio educativo. As crianças com atraso mental necessitam de uma educação apropriada, cuja denominação genérica é "educação especial". Talvez a denominação não seja muito feliz, pois, de certa forma, a educação da criança com atraso é regida pelos mesmos que educação de qualquer criança e, por outro lado, toda educação tem muito de especial, no sentindo de ser especifica e individualizada para determinados alunos (COLL; PALACIOS; MARCHESI, 1995, p. 240).

Em 2016, foi publicada a Nota Técnica n. 25 (BRASIL, 2016b), que dispõem sobre a escolarização das crianças com microcefalia. Essa nota enfatiza que a participação da criança com microcefalia deve ocorrer em diferentes espaços do ambiente educacional e dá ênfase à necessidade de um trabalho intersetorial. Destaca-se ainda, a necessidade da garantia do Atendimento Educacional Especializado - AEE nas redes públicas e particulares de ensino, conforme preconiza o Plano Nacional de Educação - PNE, que passou a vigorar com a promulgação da Lei n 13.005/2014 (BRASIL, 2014).

O atendimento educacional especializado tem como função identificar, elaborar e organizar recursos pedagógicos e de acessibilidade que eliminem as barreiras para a plena participação dos alunos, considerando suas necessidades específicas [...]. Esse atendimento complementa e/ou suplementa a formação dos alunos 
com vistas à autonomia e independência na escola e fora dela (BRASIL, 2008, p. 15).

Diante do AEE, as crianças com microcefalia devem ter acesso ao conjunto de cuidados próprios da primeira infância e, sobretudo, àqueles que sua condição específica demanda. Sabendo que as crianças com microcefalia também podem aprender quando estimuladas precocemente. Para isso, as creches devem acolhêlas em ambientes inclusivos, ricos e estimulantes, que ofereçam, por meio de ação interdisciplinar, as condições necessárias ao seu desenvolvimento integral (DA SILVA et al., 2018).

Toda educação deve começar precocemente, mesmo a da criança que evolui e progride normalmente. Por isso mesmo, deve-se começar precocemente _ desde as primeiras semanas de vida e, indubitavelmente, antes do ingresso na escola - a educação da criança com problemas de desenvolvimento, quaisquer que sejam estes problemas, e muito mais, quando se trata de deficiência mental. A deteç̧ão precoce dos problemas de desenvolvimento contribui para orientar adequadamente, os programas educacionais, nesses primeiros anos (COLL; PALACIOS; MARCHESI, 1995 p. 247).

As crianças com microcefalia interagirão com o meio no seu ritmo e tempo próprio, esses não são diferentes. Sendo assim, a discussão sobre o processo de incluir medidas que possam melhorar sua exploração do mundo, gerando possíveis ganhos e avanços na qualidade de vida desses (SANTOS 2016).

Para Santos e Rocha (2018), o grande desafio da educação é transformar as escolas em escolas inclusivas, que garantam o atendimento à diversidade humana. A partir dessas perspectivas podemos assim refletir, o qual difícil é para as crianças com microcefalia e de outras deficiências serem incluídas nas escolas da rede pública e privadas, não envolve só um ou dois fatores, mas uma série de questões sociais, culturais, políticas e econômicas.

Contudo, na atualidade às possibilidades de escolarização e inclusão no contexto escolar é uma conjuntura que se faz presente entre muitas famílias: como será o futuro dessas crianças? Entre tantas dúvidas, surgem também, questionamentos sobre a vida escolar dessas crianças. Chamando a sociedade a refletir sobre a inclusão de crianças com microcefalia no ensino regular. É preciso 
garantir o direito e a permanência dos alunos com necessidades especiais nas escolas regulares de ensino. Dessa forma, emergiu a seguinte questão norteadora: Como está ocorrendo o processo de inclusão das crianças com microcefalia nas escolas?

"A Constituição de 1988 prescreve a inclusão total e incondicional dos alunos, sendo verdadeiramente revolucionária vanguardista e muito clara ao se pronunciar sobre o direito de todos à educação. Falta-nos zelar para que suas prescrições sejam colocadas em prática, por meio de políticas educacionais que as respeitem e as consolidem nas nossas escolas" (MANTOAN, et al., 2006, p.98).

O planejamento no âmbito das políticas públicas deve ofertar a essas crianças que já chegam ao mundo concitando do poder público medidas emergenciais para que se possa efetivar e garantir seus direitos de cidadãos e dignidade a vida segundo a nossa carta magna, a constituição federal de 1988 (SANTOS, 2016).

"As dificuldades e os desafios postos pela inclusão escolar são das mais variadas ordens e estão ligados à organização da nossa sociedade, aos valores que nela prevalecem às prioridades definidas pelas políticas públicas, aos meios efetivamente disponibilizados para a efetivação dessas políticas, aos fatores relacionados à formação de docentes, às questões de infraestrutura e aos problemas relacionados à especificidade das diferentes condições que afetam o desempenho acadêmico e a formação pessoal de sujeitos que apresentam deficiências ou outras características que os introduzem na categoria de alunos especiais" (GÓES; LAPLANE, 2004, p. 2).

Assim, o objetivo desse estudo foi analisar estudos acerca do processo de inclusão de crianças com microcefalia no ensino regular de escolas públicas e privadas. Considerando a relevância dessa temática registrada nos bancos de dados Scientific Electronic Library Online (SciELO) e Google Acadêmico por intermédio de uma revisão integrativa. A revisão integrativa é um método que proporciona a síntese de conhecimento e a incorporação da aplicabilidade de resultados de estudos significativos na prática. 


\section{MÉTODO}

Realizou-se uma revisão sobre as produções científicas com base no AEE nas redes públicas e particulares de ensino. Para elaboração deste estudo, foram utilizadas as seis etapas da revisão integrativa citadas por Souza e colaboradores (2010), com o intuito de organizar as informações coletadas.

$1^{a}$ etapa: elaboração da questão norteadora. É a fase mais importante da revisão, pois determina quais serão os estudos incluídos, os meios adotados para a identificação e as informações coletadas de cada estudo selecionado.

$2^{\mathrm{a}}$ etapa: busca ou amostragem na literatura. Está relacionada à fase anterior, a busca em base de dados deve ser ampla e diversificada. Contemplando a procura em bases eletrônicas, manuais e periódicos. As referências descritas nos estudos selecionados, o contato com pesquisadores e a utilização de material não publicado.

$3^{a}$ etapa: coleta dos dados. Assim para se extrair os dados dos artigos selecionados, faz-se necessária a utilização de um instrumento previamente elaborado capaz de assegurar que a totalidade dos dados relevantes seja extraída, minimizar o risco de erros na transcrição, garantir precisão na checagem das informações e servir como registro.

$4^{a}$ etapa: análise crítica dos estudos incluídos. Esta fase demanda uma abordagem organizada para ponderar o rigor e as características de cada estudo.

$5^{\text {a }}$ etapa: discussão dos resultados. Nesta etapa, identificar-se possíveis lacunas do conhecimento e também é possível delimitar prioridades para estudos futuros.

$6^{\text {a }}$ etapa: apresentação da revisão integrativa. Essa deve ser clara e completa para permitir ao leitor avaliar criticamente os resultados. Deve conter, então, informações pertinentes e detalhadas, baseadas em metodologias contextualizadas, sem omitir qualquer evidência relacionada.

O universo da pesquisa foi composto por artigos, resumos, relatos de experiências e anais. Foram determinados os seguintes critérios de inclusão: 
estarem disponíveis em texto completo na base de dados do SciELO - Scientific Electronic Library Online (inclusos em outras bibliotecas, como Medline, Pubmed e Lilacs) e também Google Acadêmico. Sem recorte temporal, no idioma português. Utilizaram-se as palavras-chave microcefalia AND inclusão. A coleta de dados deuse de janeiro a abril de 2019. Para a padronização dos resultados utilizou-se um formulário perante a seguinte padronização: autor, identificação do artigo, ano, origem da publicação e formato do estudo. Na busca inicial em conformidade com os critérios de inclusão, foram localizados 203 estudos, 196 não respondiam à questão norteadora da pesquisa o que resultou na seleção de 07 estudos para compor a amostra da presente pesquisa.

\section{RESULTADOS E DISCUSSÕES}

Dos 07 estudos que responderam aos objetivos da pesquisa, 05 foram publicados no ano de 2017 e apenas 02 em 2018. No quadro a seguir estão dispostos os estudos que compõem a amostra dessa revisão.

Quadro 1. Síntese dos estudos que compõem a amostra.

\begin{tabular}{|c|c|c|c|c|}
\hline Ordem & $\begin{array}{l}\text { Autor } \\
\text { A n o d e } \\
\text { publicação }\end{array}$ & Título & $\begin{array}{l}\text { Origem da } \\
\text { Publicação }\end{array}$ & $\begin{array}{l}\text { Formato do } \\
\text { estudo }\end{array}$ \\
\hline Estudo 01 & $\begin{array}{l}\text { LIMA, R.R. A, et } \\
\text { al., } 2017 .\end{array}$ & $\begin{array}{l}\text { I NCLUS Ã O D O A L U NO C O M } \\
\text { MICROCEFALIA: a realidade das escolas } \\
\text { públicas e privadas de Pernambuco }\end{array}$ & Anais & $\begin{array}{l}\mathrm{R} \text { e s u } \mathrm{mo} \\
\text { Expandido }\end{array}$ \\
\hline Estudo 02 & $\begin{array}{l}\text { M E R C A D O } \\
\text { E.L.O, } 2017 .\end{array}$ & $\begin{array}{l}\text { CENÁRIO DAS CRIANÇAS COM A } \\
\text { SÍNDROME CONGÊNITA DO ZIKA E } \\
\text { SUAS FAMÍLIAS EM MACEIÓ: caminhos } \\
\text { para construção de políticas educacionais }\end{array}$ & Anais & Resumo \\
\hline Estudo 03 & $\begin{array}{l}\text { DA SILVA, I.S, } \\
2017 .\end{array}$ & $\begin{array}{l}\text { MÚSICA E INCLUSÃO NA EDUCAÇÃO } \\
\text { INFANTIL: uma perspectiva para o } \\
\text { desenvolvimento da criança com } \\
\text { microcefalia }\end{array}$ & Revista & $\begin{array}{l}\text { Relato de } \\
\text { Caso }\end{array}$ \\
\hline Estudo 04 & $\begin{array}{l}\text { NEPOMUCENO, } \\
\text { S; ALCANTARA, } \\
\text { E.F.S, } 2017\end{array}$ & $\begin{array}{l}\text { A PSICOPEDAGOGIA EM BUSCA DE } \\
\text { AJUDA À GERAÇÃO MICROCEFALIA. }\end{array}$ & Revista & Artigo \\
\hline Estudo 05 & $\begin{array}{l}\text { SEIBT, M.T.S, } \\
2017 .\end{array}$ & $\begin{array}{l}\text { Educação Especial e Inclusiva, um Novo } \\
\text { Desafio Escolar: Microcefalia. }\end{array}$ & Revista & Artigo \\
\hline
\end{tabular}




\begin{tabular}{|l|l|l|l|l|}
\hline Estudo 06 & $\begin{array}{l}\text { DA SILVA, F.C, et } \\
\text { al., 2018. }\end{array}$ & $\begin{array}{l}\text { Capacitação para profissionais de } \\
\text { Educação Infantil sobre as necessidades } \\
\text { educacionais de crianças com Síndrome } \\
\text { Congênita do Vírus Zika e outras } \\
\text { alterações neurológicas }\end{array}$ & $\begin{array}{l}\text { R e I a to de } \\
\text { Experiência }\end{array}$ \\
\hline Estudo 07 & $\begin{array}{l}\text { S A N T O S ; } \\
\text { ROCHA, 2018 }\end{array}$ & $\begin{array}{l}\text { Inclusão de crianças com microcefalia na } \\
\text { educação infantil: quais dificuldades } \\
\text { encontradas pelos professores? }\end{array}$ & Anais & $\begin{array}{l}\text { R e s u m o } \\
\text { Expandido }\end{array}$ \\
\hline
\end{tabular}

Fonte: Elaborado pela autora.

No estudo 01 de Lima e colaboradores (2017), que teve como objetivo identificar se os professores da Educação Infantil das escolas regulares estão capacitados para ensinar crianças com microcefalia, fazendo um comparativo daqueles que trabalham na rede pública e na rede particular de ensino. Sendo três da rede pública e as outras três da rede privada, todas elas localizadas na Região Metropolitana do Recife. O estudo demonstrou que $100 \%$ dos participantes que responderam ao questionário, seja da rede pública ou privada, não se sentem capacitados para receber as crianças com microcefalia, além disso, muitos deles informaram que a instituição que trabalha não possui uma infraestrutura adequada.

Para Da Silva (2018), ao falarmos das limitações e potencialidades das crianças com microcefalia, percebemos o receio e o medo de não sabermos lidar com elas, pois em grande parte dos casos, há a presença de mais de uma deficiência, as alterações visuais, motoras e auditivas são variadas e poderá interferir na realização de atividades cotidianas, como também, requerer serviços de apoio para a escolarização. A formação em AEE envolve saberes que englobam: formação pessoal e profissional produzidos pelas ciências humanas da educação; saberes disciplinares que envolvem a formação inicial e continuada nas diferentes áreas do conhecimento; saberes curriculares relacionados ao projeto de ensino que agregam aos conteúdos, métodos, técnicas de ensino para a formação dos alunos; a proposta no âmbito da escola que reúnem os saberes da experiência, da prática cotidiana que provém da cultura (SEIBT, 2017).

Diante do exposto percebe-se que a capacitação do docente para trabalhar com a inclusão de alunos com microcefalia engloba muito mais do que a formação pessoal e profissional. O docente deve ter a predisposição para perceber o aluno como ser cognocente e se perceber como sujeito importante no desenvolvimento 
dele, isso se traduz como uma questão urgente a ser enfrentada no trabalho com os professores que recebem alunos com microcefalia. Para isso, torna-se necessário o direcionamento de políticas públicas.

Para Sequeiros (2000), educar não é somente uma questão de experiência ou de boa vontade. Educar é uma tarefa complexa, que hoje está nas mãos de profissionais: professores e educadores. No mundo todo, muitos educadores dedicam a vida refletindo e pesquisando e inovando a educação.

Um projeto educativo deve estar fundamentado em teoria educativa consistente e coerente. Uma teoria educativa deve estar solidificada em uma determinada concepção da sociedade no ser humano, na ação civil e politica. Em síntese, sobre esse projeto deve existir uma antropologia e uma opção social politica abrangente (SEQUEIROS, 2000).

Sendo assim, cabe ao professor especializado em educação especial a elaboração do plano da AEE; identificação e seleção dos recursos de tecnologias assistivas necessários; produção e adequação de materiais e brinquedos; acompanhamento do uso dos recursos verificando sua funcionalidade; análise do mobiliário e orientação às famílias quanto aos recursos de acessibilidade a serem utilizados (BRASIL, 2015).

No estudo de Lima e colaboradores (2017), percebeu-se que a discussão central gira em torno do aperfeiçoamento profissional para a escolarização dessas crianças. Sabemos que se faz necessário também, adequar o ambiente físico, os recursos pedagógicos e os materiais escolares necessários, conforme as proposições da Política Nacional de Educação Especial, o que as torna possibilidades importantes no contexto da educação inclusiva.

Para os autores da pesquisa, embora existam leis para efetivar a educação inclusiva, à realidade nas escolas foge dos padrões pré-estabelecidos, onde, de maneira geral, tanto as escolas públicas quanto as privadas analisadas estão sem condições de formularem um plano de trabalho inclusivo para atender as crianças que possuem microcefalia. Visto isto, é de grande importância que haja mudanças na infraestrutura e que esses professores se tornem capacitados para receberem os alunos com microcefalia (LIMA et al., 2017). 
É sabido que a inclusão escolar do educando com necessidades educacionais especiais é um tema de grande relevância nos debates educacionais. Acredita-se que a escola deve atender às diferenças intrínsecas dos alunos. Quando se trata de crianças com microcefalia é preciso compreender que essa é uma síndrome recente e que o desenvolvimento escolar desses alunos parece-nos ser mediado perante um processo qualitativamente diferente.

Já no estudo 02 de Mercado (2017) que se dedicou a identificar o cenário de crianças com a síndrome congênita do Zika vírus e suas famílias em Alagoas, com o intuito de provocar o poder executivo à elaboração de políticas públicas que garantam a estas crianças o direito à educação infantil, evidenciou-se a necessidade dos municípios e estado definirem políticas educacionais que possam garantir desde a matrícula em creche e pré-escolas à oferta de AEE e profissional de apoio escolar as crianças com microcefalia. Uma vez que o estado não dispõe de um plano de inclusão individual para crianças com microcefalia.

Para Mercado (2017) é preciso entender que, o processo de inclusão escolar envolve além do acesso, a permanência, o aprendizado e desenvolvimento pleno de crianças com a Zika vírus, a partir de programas de formação continuada de professores e profissionais, a reestruturação das instituições de Educação Infantil.

O estudo de Mercado (2017), relata que se faz necessário enfrentar esse desafio e construir projetos capazes de superar os processos históricos de exclusão. Tendo como objetivo promover as transformações nos sistemas de ensino para assegurar o acesso e a permanência de todos na escola, perante a reestruturação das instituições de Educação Infantil. O estudo 03 de Da Silva (2017), que teve como objetivo relatar a contribuições da música para o desenvolvimento do aluno com microcefalia. Para o autor, ainda há um enorme caminho para que a educação musical chegue a ser acessíveis as pessoas com deficiência em sua totalidade.

Para essa prática temos a Lei $N^{\circ} 11.769$ sancionada pelo presidente Luís Inácio no dia 18 de agosto de 2008, que estabelece a obrigatoriedade do ensino de música nas escolas de educação básica. Essa lei acrescenta ao artigo 26 da Lei 9394/96 o seguinte: com essa legislação, o ensino de música deverá estar presente na educação básica, o que implica também sua presença na Educação Infantil e Anos Iniciais (MOREIRA; SANTOS; COELHO, 2014). 
A música auxilia no desenvolvimento social e cultural da criança. Ela também tem valor incontestável no desenvolvimento cognitivo pelo seu poder de aguçar a linguagem, a memória, a imaginação, a atenção e várias outras habilidades da criança (SILVA, 2016). É muito importante conviver com a música desde muito pequeno. A música quando bem trabalhada desenvolve o raciocínio, criatividade e outros dons e aptidões, por isso, deve-se aproveitar esta tão rica atividade educacional dentro das salas de aula (MOREIRA; SANTOS; COELHO, 2014).

Para Moreira e colaboradores (2014), antigamente, a música era considerada como fundamental para a formação dos futuros cidadãos, ao lado da Matemática e Filosofia. A música sempre esteve no contexto da educação ao longo de sua história, atendendo a vários propósitos, como formação de hábitos, atitudes e comportamentos. Para Bueno (2011), a musicalidade está dentro de cada pessoa, para tanto, há várias formas de se trabalhar a música na escola, por exemplo, de forma lúdica e coletiva, utilizando jogos, brincadeiras de roda e confecção de instrumentos. Sendo a imaginação uma grande aliada nesse quesito.

É sabido que a educação no Brasil, ao longo do tempo, vem sofrendo diversas transformações e muitas das suas leis, no que se refere à educação, inclusive a educação inclusiva, ainda atravessam distanciamento do preconizado. No entanto, a música ao longo desse processo de construção do conhecimento vem ganhando reconhecimento em todos os cenários educacionais.

O estudo 04 de Nepomuceno e Alcântara (2017), analisou à importância da escola e dos professores diante dos problemas de aprendizagem do aluno com microcefalia. Esse discorre sobre o processo humano do conhecimento e seus padrões evolutivos saudáveis e patológicos, bem como a influência (família, escola, sociedade) no seu desenvolvimento. Esse ainda buscou mostrar a importância da interação da psicopedagogia para amenizar o desgaste emocional e profissional que pode vir a fazer parte da rotina das escolas ao receberem crianças com microcefalia, facilitando o desempenho do educador e do educando na tarefa de levar e receber conhecimento.

Estudos realizados em países desenvolvidos, como os Estados Unidos, têm demonstrado que os processos proximais vivenciados na família e na escola podem atuar como fatores de proteção para alunos que se encontram diante de 
adversidades individuais ou sociais (PETRUCCI; BORSA; KOLLER, 2016). Essa compreensão pode incentivar a elaboração de intervenções voltadas para o contexto familiar e escolar de forma integrativa. Para Petrucci e colaboradores (2016), o papel da família perante o contexto de desenvolvimento da criança, destaca-se nos processos proximais que ocorrem entre a criança e os seus primeiros cuidadores.

Em seguida, destaca-se o papel da escola como segundo contexto de desenvolvimento, enfatizando-se os processos proximais que ocorrem entre estudantes e professores. Assim o relacionamento da criança com os pais e com os professores, os quais, de acordo com o modelo bioecológico, são considerados como processos proximais fundamentais para o desenvolvimento humano (PETRUCCI, 2016). O modelo Bioecológico do Desenvolvimento Humano (MBDH) é um sistema teórico e metodológico para o estudo científico do desenvolvimento humano ao longo do tempo. Esse faz análise do desenvolvimento e considera a interação sinérgica de quatro componentes: Processo, Pessoa, Contexto e Tempo (BRONFENBRENNER; MORRIS, 1998).

O estudo 05 de Seibt (2017), que teve como objetivo analisar os obstáculos encontrados no processo de inclusão escolar de crianças com microcefalia. Esse demonstrou que os professores entrevistados apresentaram diversos pontos de vista frente à inclusão de crianças com microcefalia, para eles: é um desafio a ser alcançado, pois essa nova patologia causa preocupações e receios, tendo em vista que é uma situação nova. O estudo ainda relata que as principais dificuldades encontradas em sala de aula são: a falta de profissionais com formação específica para área da Educação Especial, falta de materiais pedagógicos, acessibilidade e recursos avaliativos (SEIBT, 2017). Observa-se que o estudo de Seibt (2017) corrobora com o estudo de Lima e colaboradores (2017). Tendo como foco central a formação dos docentes ainda como principal problema para o bom acolhimento no processo de inclusão de crianças com microcefalia.

No estudo 06 de Da Silva e colaboradores (2018) que teve o objetivo, capacitar 30 profissionais de Educação Infantil na cidade de Maceió, no estado de Alagoas sobre as necessidades educacionais de crianças com Síndrome Congênita do Zika vírus e outras alterações neurológicas, demonstrou que há necessidade de promover mais ações que colaborem na preparação e organização dos serviços de 
Educação Infantil. Segundo os autores para atender essa perspectiva da inclusão, é necessário estabelecer práticas pedagógicas que capacitem os profissionais, para atender as necessidades apresentadas pela demanda e serviços de apoio permanentes, por meio de consultorias colaborativas.

O estudo ainda ressaltou que para a tomada de decisão e identificação das necessidades educacionais das crianças com microcefalia, a avaliação realizada pela escola deve contar com a experiência dos profissionais da escola, do setor responsável pela Educação Especial, da família e cooperação dos serviços de saúde (DA SILVA et al., 2018). Para Da Silva (2018), a identificação dessas necessidades está condicionada ao conhecimento das limitações e as potencialidades das crianças com microcefalia por equipe multidisciplinar. Apesar de informar sobre esses aspectos de maneira generalizada, é importante enfatizar que as crianças devem ser avaliadas individualmente, respeitando suas particularidades.

Vale ressaltar que as contribuições dos profissionais de saúde no contexto educacional podem ser entendidas como um recurso adicional que viabiliza estratégias educacionais inclusivas, favorecendo o desenvolvimento da criança em todas as suas necessidades (BALEOTTI; ZAFANI, 2017). Vale acrescentar que a saúde e educação podem e devem andar juntas. As intervenções da área da saúde são fundamentais para que as intervenções educacionais sejam eficazes. Professores e profissionais de saúde devem trabalhar como cooperadores no processo de ensino e aprendizagem. Assim o desenvolvimento acontecerá de maneira global.

No estudo 07 de Santos e Rocha (2018), foram escolhidas quatro escolas da Educação Infantil, duas da rede pública e duas da rede privada situadas no município de Jequié - BA. Nesse estudo avaliou-se a estrutura da escola, a formação dos professores e a preparação para acolher crianças com microcefalia e outras deficiências. $O$ estudo evidenciou que as escolas não têm estrutura física adequada para receber crianças com microcefalia. Como também, constatou-se que a secretaria de educação não dá o apoio necessário à inclusão de crianças com necessidades especiais. Os profissionais também relataram não receber cursos de aperfeiçoamento. Já os professores da rede privada relataram não ter as mesmas 
condições mencionadas pelos docentes das escolas públicas. Ainda acrescentaram ter dificuldades em lidar com a socialização dos alunos com necessidades educacionais especiais, inclusive ocorre bullying quando há crianças com necessidades especiais em sala.

Assim, tendo como base a Constituição de 1988 (Brasil), a inclusão de crianças com deficiência na rede de ensino, está previsto no artigo 208 (§ III) que os portadores de deficiência devem ter atendimento especializado preferencialmente na rede regular de ensino (SANTOS; ROCHA, 2018). Para Santos e Rocha (2018), as escolas não dispõem de um espaço adequado, a maioria possui ainda escadas, falta corrimão, pista tátil, portas adequadas, estão escassas de formação em AEE, falta salas de AEE, cuidadores que prestem apoio aos professores em sala de aula e acessibilidade.

Os estudos aqui apresentados narram uma perspectiva desafiadora da inclusão, que além de gerar inquietações em toda a sociedade, descreve diversos obstáculos a serem superados, dificultando um plano individual de atendimento especial para as crianças com microcefalia. Dessa forma, os professores e toda a escola devem buscar formação necessária para realizar um bom trabalho no contexto educacional dessa criança que necessita de AEE. Torna-se necessário compreender que receber essas crianças, configura-se em ofertar um cuidado específico. Ainda é preciso ressaltar que cada criança aprende de uma forma diferente, e a criança com microcefalia vai precisar de estímulos e cuidados a mais para o seu desenvolvimento, sempre respeitando o seu grau de aprendizagem (SANTOS; ROCHA, 2018).Quanto mais precoce a inserção dessa criança, maiores chances de ganhos e avanço no desenvolvimento. Para isso, a família, a sociedade e o governo devem caminhar juntos em busca de alternativas assistivas emergentes.

É sabido que o tema da microcefalia não é algo recente, infecções por zika foram observadas em 72 países desde 2007, contudo foi a partir do surto que houve em 2015 no Brasil que muitas pesquisas começaram a se desenvolver, portanto, ainda é uma patologia que vem sendo explorada em termos de novos conhecimentos (SANTOS; ROCHA, 2018). No contexto atual há discussões necessárias sobre inclusão, aqui delimitamos em evidenciar as crianças com 
microcefalia causada por Zika vírus, e a importância do atendimento precoce, para que decorra em ganhos e avanços na sua aprendizagem.

\section{CONSIDERAÇÕES FINAIS}

Primeiramente, considera-se que este estudo possibilitou novos conhecimentos a partir da síntese das amostras, como ainda demonstrou limitações acerca do quantitativo de estudos encontrados nas bases de dados pesquisadas.

Os estudos aqui analisados relatam que as principais dificuldades ainda estão voltadas para o planejamento das ações, uma vez que deverão ter o propósito de inserir o aluno precocemente no contexto escolar, envolvendo seu grupo familiar, em um trabalho conjunto com comunidade escolar. Volvidos em um olhar crítico sobre o contexto histórico do aluno com microcefalia e sua especificidade clínica, em razão de sua valorização e oferta de oportunidades para o desenvolvimento de todas as suas potencialidades.

Outrossim, as lacunas na formação continuada dos professores especializados em educação especial consolidam-se em um desafio a ser superado na implementação das políticas de inclusão de alunos com microcefalia.

Torna-se necessário efetivar políticas públicas para o acolhimento e assistência à família e a crianças, e abrir também no campo pedagógico discussões de melhorias de prestação de serviços multidisciplinares para que se obtenham avanços progressivos dessas crianças que chegarão ou já chegaram às escolas.

É preciso dar importância ao atendimento precoce das crianças com microcefalia. Para isso, dependemos da reformulação e efetivação das políticas públicas e do envolvimento social. Essa construção coletiva beneficiará indivíduos repletos de necessidades. Para isso, torna-se necessário explicitar os problemas vivenciados na sociedade e assim, mudar o cenário atual.

$E$, por fim, observou-se que os estudos sobre a inclusão escolar dos alunos com microcefalia, ainda se encontram com pouca representatividade, sendo necessário um maior fomento em pesquisas que deem visibilidade a esse público, mas, também, é imprescindível investimento na formação dos recursos humanos 
para contribuírem com o processo de aprendizagem de todo o público alvo da educação especial com amplas necessidades.

\section{REFERÊNCIAS}

ASHWAL, S. et al. Practiceparameter: evaluationof the childwithmicro cephaly (anevidencebasedreview): reportof the Quality Standards Subcommitteeofthe American Academyof Neurologyand the Practice Committeeof the Child Neurology Society. American Academyof Neurology, v. 73, n. 11, p. 887-897, 2009. Disponível em: <https://www.ncbi.nlm.nih.gov/pmc/ articles/ PMC2744281/>. Acesso em: 20 mai. 2018.

BALEOTTI, L. R.; ZAFANI, M. D. Terapia Ocupacional e tecnologia assistiva: reflexões sobre a experiência em consultoria colaborativa escolar. Caderno Brasileiro de Terapia Ocupacional. São Carlos, v. 25, n. 2, p. 409-416, 2017. Disponível em: <http:// www.cadernosdeterapiaocupacional.ufscar.br/index.php/cadernos/article/view/1544/856>. Acesso em: 30 abr. 2019.

BARROS, S.M.M. Fortalendo a rede de apoio de mães no contexto da Sindrome Congênita do vírus Zika: Relatos de uma intervenção psicossocial e sistêmica. Nova Perspectiva Sistêmica. n. 58, p. 38-59, 2017.

BERODT,E. D. Microcefalia. Disponível em: <.http: www.compartireducacionespecial.org>. Acesso em: 20 de abr. de 2019.

BRASIL. Lei $n^{\circ} 13.005$, de 25 de junho de 2014. Aprova o Plano Nacional de Educação PNE e dá outras providências. Diário Oficial [da] República Federativa do Brasil, Brasília, 26 jun. 2014. Disponível em: <http://www. planalto.gov.br/ccivil_03/_ato2011-2014/2014/lei/ I13005.htm>. Acesso em: 23 de abr. 2019.

BRASIL. Ministério da Educação. Diretoria de Políticas de Educação Especial. Nota técnica $n^{\circ} 25 / 2016$. Orientações para o acolhimento dos bebês com microcefalia pela educação infantil. In: A consolidação da inclusão escolar no Brasil: 2003 a 2016. Brasília: Ministério da Educação, 2016b, p. 46- 47. Disponível em: <http://www.ufpb.br/cia/contents/ manuais/a-consolidacao-da-inclusao-escolar-no-brasil-2003-a-2016.pdf>. Acesso em: 23 abr. 2019.

BRASIL. Ministério da Educação. Secretaria da Educação Especial. Política nacional de Educação Especial na perspectiva da educação inclusiva. Brasília, 2008. Disponível em: $<$ http://portal.mec.gov.br/arquivos/pdf/ politicaeducespecial.pdf>. Acesso em: 20 de abr. 2019.

BRASIL. Nota Técnica Conjunta $n^{\circ}$ 02/2015. Orientações para a organização e oferta do Atendimento Educacional Especializado na Educação Infantil. Brasília, DF: MEC/ SECADI/DPEE, 2015.

BRONFENBRENNER, U.; MORRIS, P. A. The ecologyofdevelopmental processes. In: DAMON, W.; LERNER, R. M. (Orgs.). Handbook of childpsy chology. Vol. 1: Theoretical models ofhuman development. New York: John Wiley, v.1, n.1,p. 993-1028, 1998.

BUENO, Roberto. Pedagogia da Música. v.1, Jundiaí: Keyboard, 2011. 
COLL, C.; PALACIOS, J.; MARCHESI, A. Desenvolvimento psicológico e educação: necessidades educativas especiais e aprendizagem escolar. v. 3, p. 247. Porto Alegre: Artes Médicas, 1995.

DA SILVA, F. C; VITAL, M. D. S; SANTOS, R . C. C: DA CRUZ, T. A. R; CALHEIROS, D. S. Capacitação para profissionais de Educação Infantil sobre as necessidades educacionais de crianças com Síndrome Congênita do Vírus Zika e outras alterações neurológicas. Educação, Batatais, v. 8, n. 1, p. 57-71, jan./ jun. 2018.

DA SILVA, F. C. et al. Capacitação para profissionais de Educação Infantil sobre as necessidades educacionais de crianças com Síndrome Congênita do Vírus Zika e outras alterações neurológicas. Educação Batatais, São Paulo, v. 8, n. 1, p. 57-71, jan./ jun. 2018.

DA SILVA, I. S. Música e inclusão na educação infantil: uma perspectiva para o desenvolvimento da criança com microcefalia. Revista Includere. Rio Grande do Norte, v. 3. n. 1, 2017.

GÓES, M. C. R.; LAPLANE, A. L. F. Apresentação. In: GÓES, M.C. R.; LAPLANE, A. L. F. (Orgs.) Políticas e práticas de educação inclusiva. Campinas: Autores Associados. p. 1-5, 2004.

LIMA, R. R. A, et al. Inclusão do aluno com microcefalia: A realidade das escolas públicas e privadas de Pernambuco. IV Congresso Nacional de Educação. João Pessoa. 2017. Disponivel em:<www.conedu.com.br>. Acesso em: 12 de mai. 2019.

MANTOAN, M.T. É.; et al. Inclusão Escolar: pontos e contrapontos. São Paulo: Sumus, 2006.

MARCELLI D; COEH, D. Infância e Psicopatologia. 8ª ed. Porto Alegre: Artmed, 2010.

MARINHO, F. Microcefalia no Brasil: prevalência e caracterização dos casos a partir do Sistema de Informações sobre Nascidos Vivos (Sinasc), 2000-1015, 2016. Disponível em: <http://www.scielo.br/scielo.php?script=sci_arttext\&pid=S2237-96222016000400701\#aff1>. Acesso em: 12 de mai.2019.

MERCADO, E. L. O. Cenário das crianças com a síndrome congênita do Zika e suas famílias em Maceió: Caminhos para construção de políticas educacionais. VII ENCONTRO ALAGOANO DE EDUCAÇÃO INCLUSIVA. II ENCONTRO NORDESTINO DE INCLUSÃO NA EDUCAÇÃO SUPERIOR. Maceió, 2017. Disponível em: https:<//www.google.com/

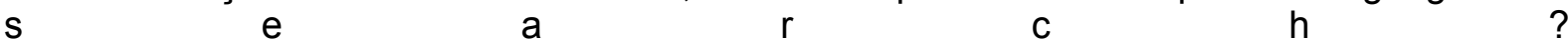
ei=vz4tw4qyk8qkwgsj6qzwdg\&q=cenário+das+crianças+com+a+síndrome+congênita+do+zi ka+e+suas+famílias+em+maceió >. Acesso em: 01 de mai. 2019.

MINISTÉRIO DA SAÚDE. Secretaria de Atenção à Saúde. Secretaria de Vigilância em Saúde. Plano Nacional de Combate ao Aedes aegypti e suas consequências. Orientações integradas de vigilância e atenção à saúde no âmbito da Emergência de Saúde Pública de Importância Nacional. $1^{a}$ versão. Brasília: Ministério da Saúde, 2016a. Disponível em: <http://combateaedes.saude.gov.br/ images/pdf/orientacoes-integradas-vigilanciaatencao.pdf>. Acesso em: 23 abr. 2019.

MOREIRA, A. S; SANTOS, H; COELHO, I. S. A música na sala de aula: A música como recurso didático. UNISANTA Humanitas, v. 3, n. 1,p. 41-61, 2014. 
NEPOMUCENO, S; ALCANTARA, E. F. S. A Psicopedagogia em busca de ajuda à geração microcefalia. Volta Redonda - RJ: Rev. Episteme Transversalis. v.11, n.2, p. 107-118, jul./dez.2017.

PETRUCCI, G. W; BORSA, J. C; KOLLER, S. H; PETRUCCI, G. W; BORSA, J. C., KOLLER, S. H. A Família e a escola no desenvolvimento socioemocional na infância. Trends in Psychology. Temas em Psicologia, v. 24, n. 2, p. 391-402, abr./jun, 2016.

SANTOS, D. R.; ROCHA, M. R. Inclusão de crianças com microcefalia na educação infantil: quais dificuldades encontradas pelos professores? Actas Del Congreso Iberoamericano de Docentes.ISBN: 978-84-948417-0-5. Artículo 1340. 2018. Disponível em: <http://congreso.formacionib.org/1340.pdf>. Acesso em 19 de mai. 2019.

SANTOS, M. M. S F. Inclusão na educação infantil: Microcefalia e a importância da estimulação precoce. WEBARTIGOS. 2016. Disponível em: <https://www.webartigos.com/ artigos/inclusao-na-educacao-infantil-microcefalia-e-a-importancia/147340>. Acesso em 26 de abr. 2019.

SEIBT, M. T. S. Educação Especial e Inclusiva, um Novo Desafio Escolar: Microcefalia. Revista Científica Multidisciplinar Núcleo do Conhecimento. Edição 9. Ano 02, Vol. 01. p. 130-147, dez. de 2017.

SERQUEIROS, L. Educar para solidariedade. Porto Alegre: Artes Médicas, 2000.

SILVA, K. S. A música na escola e seu papel pedagógico na educação infantil. Revista Even. Pedagóg, v. 7, n. 2, p. 359-370, jun./jul. 2016.

SOUZA, M. T.; SILVA, M. D.; CARVALHO, R. Revisão integrativa: o que é e como fazer. Revista Einstein, São Paulo, v. 8, n. 1, p. 102-106, 2010. 